Кривов Максим Викторович, к.т.н., доцент, Ангарский государственный технический университет, e-mail: vmk@angtu.ru

ФОРМЫ АБСТРАКЦИИ КОНФИГУРАЦИИ ЗАПОРНОЙ АРМАТУРЫ ПРИ МОДЕЛИРОВАНИИ ПОТОКОВ В ТРЕНАЖЕРНОЙ МОДЕЛИ

\title{
FORMS OF ABSTRACTION OF THE VALVES CONFIGURATION WHEN MODELING FLOWS IN THE TRAINING MODEL
}

\begin{abstract}
Аннотация. Рассматриваются подходы к информационному описанию различных типов конфигурации запорной арматуры при моделировании технологических потоков в тренажерных моделях компьютерных тренажерных комплексов.

Ключевые слова: компьютерный тренажерный комплекс, тренажерная модель, модель потоков, структурный синтез модели.

Abstract. Approaches to information description of various types of valves configuration are considered when modeling process flows in training models of computer simulator complexes.

Keywords: computer training complex, training model, flow model, structural model synthesis.
\end{abstract}

При структурно-параметрическом синтезе тренажерных моделей [1] важно определить достаточную для информационного описания потока форму абстракции, позволяющую обобщить любые существующие в реальности конфигурации запорной арматуры на технологических потоках.

Для описания потока определим его информационной моделью в виде кортежа:

$$
F W_{i}=\left\langle\text { Source, } \operatorname{Sink}, T, P, F, C_{j} \ldots V S, S F\right\rangle,
$$

где $i=\overline{1, n}$ - индекс потока; Source - источник потока; Sink - приёмник потока; $T$, $P, F$ - температура, давление, расход потока; $C_{j}$ - концентрации $j$-го компонента $(j=\overline{1, m})$ в потоке и др.; $V S$ - модель конфигурации отсечной арматуры потока; $S F$ - модель предохранительного клапана.

На основе анализа технологических процессов предлагается следующая абстрактная модель блока запорной арматуры и регулирующих клапанов (рисунок 1), где объекты с обозначением Z1-Z5 - это модели запорных вентилей или аналогичной технологической арматуры; объект $C V$ на схеме - модель регулирующего клапана; объект Z6 - представляет модель трёхходового клапана, эквивалентную модели задвижки или заслонки, которая логически разделена на две части - левую и правую секции.

Скалярная характеристика моделей запорной арматуры - степень открытия арматуры - непрерывная величина в диапазоне $P=[0,1]$, учитываемая в выражении (2) для определения расхода потока.

Коэффициент проходного сечения модели эквивалентной арматуры определяется выражением:

$$
\xi=\left(P_{Z 2} \cdot P_{C V} \cdot P_{Z 3}+P_{Z 5}\right) \cdot P_{Z 1} \cdot P_{Z 4} \cdot\left(P_{Z 6 L}+P_{Z 6 R}\right)
$$




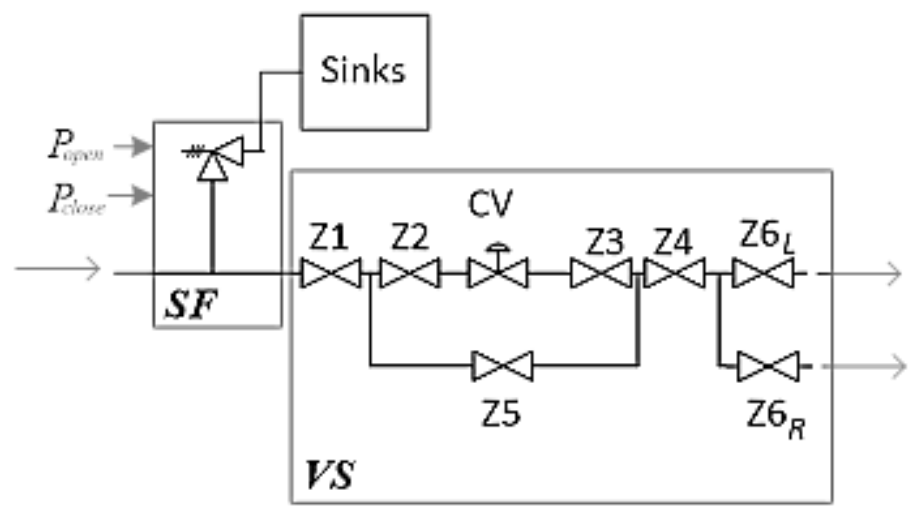

Рисунок 1 - Модель абстрактного блока запорной арматуры и клапанов

В таблице 1 приведены наиболее распространенные конфигурации арматуры на потоках, определяемые с помощью абстрактной модели.

Таблица 1

Конфригурации запорной арматуры потоков

Конфигурация

Предлагаемый подход апробирован для описания технологических трубопроводов с газовыми, парогазовыми и жидкостными средами. Предложенная модель сущностей легко преобразуется в структуру любой базы данных.

\section{ЛИТЕРАТУРА}

1. Кривов М.В., Благодарный Н.С. Динамический структурный синтез тренажерных моделей / Кривов М.В., Благодарный Н.С., Кобозев В.Ю., Колмогоров А.Г.// Сборник научных трудов Ангарского государственного технического университета. 2016. Т. 1. № 1. С. 131-138. 